\title{
Cenários arqueológicos e os festivais pré-colombianos como mediadores de práticas turísticas
}

\section{Archaeological scenarios and the pre-Columbian festivals as mediators of turism practices}

\author{
Sergio Antônio Santos Jr (SANTOS JÚNIOR, S. A.) ${ }^{*}$
}

\begin{abstract}
RESUMO - O presente artigo é constituído de três textos distintos, mas que se combinam por um denominador comum: trata-se de festivais pré-colombianos, enquanto as últimas manifestações culturais e ritualísticas indígenas nas Américas, com as respectivas ocorrências em seus sítios arqueológicos, onde originalmente foram idealizados para tal feito. O objetivo é descrever estes eventos de interesse para o turismo: "festival Tapati, Inti Raymi e festival de Vida e Morte", e sua intrincada relação com a natureza do lugar. Cabe destacar que estes dois quesitos enredados são considerados pela United Nations Educational Scientific and Cultural Organization - UNESCO, como Patrimônios Culturais da Humanidade, no que se refere ao material e ao imaterial. A estratégia teórico-metodológica desta abordagem compreende dois processos: o primeiro, destaca a importância destes lugares, segundo parecer da Assessoria de Avaliação da UNESCO e de seus documentos disponibilizados em relação ao sítio; o segundo, inspira-se na etnografia urbana, onde foram recolhidas impressões e relatos de alguns viajantes, pesquisadores, entidades público/privadas e do próprio autor.
\end{abstract}

Palavras-Chave: Turismo; Festivais pré-colombianos; Sítios Arqueológicos; Tapati; Inti Raymi; Festival de Vida e Morte.

ABSTRACT - The present article is made up of three distinct texts, but which combine by a common denominator: they are pre-Columbian festivals, while the last indigenous cultural and ritualistic manifestations in the Americas, with their occurrences in their archaeological sites, where originally were designed by this purpose. The objective of this work is to describe these tourism events: "Tapati festival, Inti Raymi and festival of life and death", and its own intricate relationship with the place. It should be noted that these two issues are considered by the United Nations Educational Scientific and Cultural Organization (UNESCO) as Cultural Patrimony of Humanity, both material and immaterial. The theoretical and methodological strategy of this approach comprises two processes: the first, highlights the importance of these places, according to the advice of the Evaluation Evaluation of UNESCO and its documents made available in relation to the site; The second is inspired by the urban ethnography, where impressions and reports of some travelers, researchers, public / private entities and the author were collected.

Key words: Tourism; Pre-Columbian Festivals; Archaeological Sites; Tapati; Inti Raymi; Festival for Life and Dead.

\footnotetext{
* Formação: Graduação em Turismo pela Universidade Bandeirante de São Paulo (USB), Graduação em Arquitetura e Urbanismo pela Universidade Anhanguera (UNIAN), Mestrado em Arquitetura e Urbanismo pela Universidade Presbiteriana Mackenzie (UPM) e Doutorando em Arquitetura e Urbanismo pela Faculdade de Arquitetura e Urbanismo da Universidade de São Paulo (FAU-USP). Atividade profissional: Arquiteto do escritório SC - Construções. Endereço físico para correspondência: Rua Juan Vicente, 482. CEP: 06160-180 - Osasco - São Paulo/SP - Brasil. E-mail: arquiteturismologo.sergio@gmail.com
} 


\section{INTRODUÇÃO}

O artigo a seguir foi elaborado a partir de três textos distintos, que parecem não combinarem entre si porque, em geral, trata-se de diferentes pontos no espaço e no tempo, mas que se concluem a partir de um denominador comum: são festivais précolombianos, ou seja, as últimas manifestações indígenas nas Américas e que ainda ocorrem no lugar em que foram originalmente idealizados para tal feito e, atualmente, tornaram-se atrativos turísticos. Ressalta-se também que essas duas instâncias analisadas são consideradas pela United Nations Educational Scientific and Cultural Organization - UNESCO, como Patrimônios Culturais da Humanidade, no que se refere ao Material e ao Imaterial; o parecer dessa entidade será constantemente indicado como fonte elucidativa, sobretudo pelos motivos que os levaram a essas considerações em torná-los patrimônio.

Assim, os textos a seguir são subsidiados em uma temática conciliadora entre as noções de Patrimônio Cultural Material e Imaterial engendrada por suas práticas de uso, portanto, antes de prosseguir se faz necessário o esclarecimento de pelo menos três chaves-conceituais interpretativas que permeiam este discurso.

A primeira chave recai sobre o espaço arquitetônico, pois, diferente das demais artes, a arquitetura é uma arte vivida e não simplesmente contemplativa. De fato, o termo "arquitetura" designa um objeto de reflexão privilegiado em face da tríade "edifício-cidade-paisagem" que marca todo e qualquer agenciamento espacial feito pelo homem. Para Milton Santos (1996), o entendimento sobre "agenciamento espacial" se estende ao domínio e modelagem do meio, o que fundamenta um evento de qualquer natureza, inclusive cultural, e, isso, justificaria de um lado, o tempo da produção e das ações comportamentais, do outro, do uso da materialidade e espacialidade pela sociedade de uma determinada época.

A segunda chave, que é complementar a primeira, incide nos princípios da preservação e do restauro, pois a natureza "pura" de um patrimônio material, nesse caso, é ilusória; haja vista as impossibilidades de se permanecerem ancorados no espaço e no tempo sem que suas "peças" sejam inalteradas. O mesmo vale para a palavra contada dos ritos, que não deixaram registros formais e, então, ressurgiram. Desse modo, surgem questionamentos sobre o par "autenticidade/verdade" daquilo que é 
contemplado como um monumento preservado passado e dos relatos memorialísticos das celebrações e seu vivido corpóreo. Mas Carsalade recorda que:

\begin{abstract}
[...] quanto às questões relacionadas ao par autenticidade/verdade [...] muitas vezes esses conceitos partem de uma ilusão sobre um suposto "documento histórico", objeto, palpável, como se também ele não fosse sujeito a manipulações e desvios e sobre os quais só temos acesso a certas partes de sua própria história. Assim, temos colocado a atenção mais no objeto de estudo e esquecido do sujeito que o estuda, como se a "verdade" ou "autenticidade" de um documento ou de um patrimônio não dependesse fundamentalmente da interação entre o que é observado e quem o observa. Qualquer que seja a sua forma, é uma herança que vem do passado e tem sua origem em um tempo que não volta mais, mas, independentemente de seu valor de "verdade", é um "objeto" do passado, com potencial de expressão próprio. Isto não quer dizer, no entanto, que ele é certamente o documento comprobatório da história e nem que ele é "original" de um determinado fato histórico ou de um único momento específico de criação: ele deve ser absolutamente relativizado como sobrevivente do passado, mas sem a aura de um inconteste "real" (CARSALADE, 2011, p. 2).
\end{abstract}

E eis que a interpretação encontra por uma via paralela a problemática da etnografia, em que se inspira este discurso: falar pelo outro. Para Sarlo (2009, p. 2) trata-se de uma discussão débil, pois ao outro "nem sabe tudo o que diz nem diz tudo o que sabe", o mesmo acontece com materiais mais argutos, como o jornalístico, quais as fontes os hauriu e o repertório do interpretante? Nisso, todos parecem iguais. Portanto, o que se absorve de tal procedimento, privilegia as vivências e as impressões registradas do momento, inclusive por imagens, enquanto ao valor de "verdade", este reside onde "o ver e o saber ocorrem ao mesmo tempo presente". Este foi o principal instrumento utilizado e apropriado em toda a pesquisa, junto à revisão bibliográfica sobre os sítios e as festividades.

A terceira e última, notadamente é onde este estudo recebe maior enfoque, vertese sobre o ângulo de apreciação das vivências, pois, explorar em termos teóricos e metodológicos o fato de que a concepção dos espaços hoje considerados sítios arqueológicos e patrimônios da humanidade, como a Ilha de Páscoa, Palenque e Sacsayhuamán, enquanto mediadores de práticas socioculturais, que se tornaram atrações turísticas, tornam-se indissociáveis àquilo que Lefebvre (1974) conceitua como "vivido", ainda que de tradições passadas transportadas às futuras gerações. Para o autor, as relações sociais são abstrações, não têm existência real a não ser no e pelo espaço, portanto, as práticas sociais seriam de fato práticas espaciais. Desse modo, 
voltar-se para o vivido é privilegiar os "corpos", enquanto "resíduos e produtos" da atividade cultural humana, não restrito apenas aos resquícios físicos do edificado, mas também ao vivido corpóreo.

Aqui, esses atributos remetem os espectadores, nacionais e estrangeiros, a um cenário composto por civilizações passadas, onde se vivenciam os significados dos ambientes e seus fins pelo momento das festividades. É fato que a utilização da categoria "passado", comparece como uma das condicionantes para a realização de tais eventos, "mas o dado dinâmico na reprodução destes eventos históricos são os próprios eventos do tempo presente", como menciona Milton Santos (1996, p. 330). Nesse entendimento e ao que tudo interessa, o restauro dos festejos - festival Tapati, Inti Raymi e a Festa aos Mortos - são analisados pelo ato contemporâneo, haja vista a impossibilidade de redesenhar a sociedade nos meandros das tessituras de épocas passadas, especialmente, seus valores culturais, seja de quem participava quanto de quem assistia. Tudo isso assegura a valoração histórica, sobretudo pelo rito, que parece garantir a identidade de um povo e sua perpetuação no espaço-tempo, um nacionalismo antropofágico com e pela participação assistida.

São estas as instâncias que viabilizaram a contextualização a seguir, pois têm a finalidade de aquilatar entre o diverso e o semelhante a ideia dos usos daquilo que seria o sentido do originalmente proposto ao edificado, ampliando, assim, o entendimento e o elo afetivo em relação a um sítio e a uma cultura local.

Sob essa perspectiva, explicita-se que, o intuito de preocupar-se com o vivido encenado vem concatenado a possibilidade histórica da vida cotidiana passada - aliás, quando fora deste tempo cíclico, do momento do evento, um lugar e o próprio tempo, parecem estar imersos às pressões do repetitivo e do linear da visitação turística, que ocultam sua verdadeira essência.

Tendo esclarecido a perspectiva teórico-metodológica, não falta muito para compreender como o advento dessas festividades pode revelar e melhor expressar os sítios arqueológicos. Durante a sistematização das informações nesta temática, objetivou-se, então, esclarecer duas indagações que embasaram esta pesquisa:

- Quais seriam as festividades das civilizações pré-colombianas na América Latina que perduravam até o tempo presente e sua possível relação em existir com e pelos sítios arqueológicos? 
- Por que estes lugares e ritos são considerados Patrimônios da Humanidade, quais os critérios estabelecidos para tal conceituação que dispunham dessa relevância mundial?

Com base nesses pressupostos, o desígnio específico verteu-se sobre a coexistência de ambos os elementos. Trata-se, por isso mesmo, de um nível analítico privilegiado por esse ângulo de apreensão, dos quais os destinos turísticos que melhor responderam a isso foram ${ }^{1}$ : a Ilha de Páscoa, de território chileno, com o festival Tapati celebrado durante primeira dezena do mês de fevereiro (GRANT-PETERKIN, 2011); subsequente, em Cusco, no Peru, tem-se o ritual Inti Raymi realizado especificamente no dia 24 de junho (EMUFEC, 2015); e por fim, cientes de que o festival de vida e morte é celebrado em todo o México, o maior enfoque recaiu sobre a cidade de Palenque, pois acredita-se que tudo começou nessa cidade durante os dias 31 de outubro a 2 de novembro (UNESCO, 2008). A indicação de tais localidades no globo terrestre podem ser visualizadas na figura 1 .

FIGURA 1 - INDICAÇÃO GEOGRAFICA DAS LOCALIDADES: PALENQUE, CUSCO E ILHA DE PÁSCOA NO GLOBO TERRESTRE.

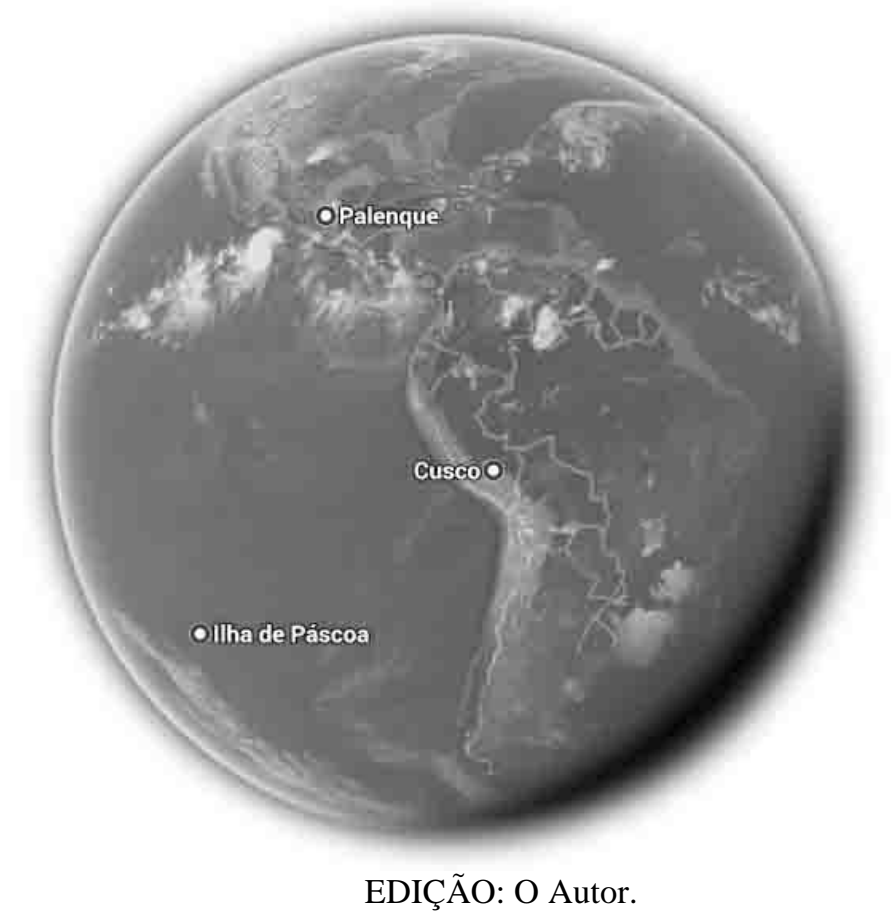

\footnotetext{
${ }^{1}$ Para se obter tal resultado, nessa pesquisa foi elaborado um banco de dados específico com três requisitos, na seguinte ordem de importância: celebração mais importante; o local de realização e país/território. (Nota do Autor - N. A).
} 
Tal dinâmica argumentativa traz nos três textos ângulos distintos de apreensão descritiva do local de pesquisa, sob uma perspectiva marcada pelo posicionamento do Comitê de Assessoria e Avaliação da $\mathrm{UNESCO}^{2}$ e, subsequente, os registros de viajantes que registraram e disponibilizaram suas vivências e relatos memorialísticos, sobretudo, online.

\section{ILHA DE PÁSCOA, CHILE: O PARQUE NACIONAL DE RAPA NUI E O FESTIVAL TAPATI}

Atentando-se a importância do lugar, de excepcional valor universal, no dia 13 de junho 1994 os arquivos da UNESCO apresentam o primeiro relatório expedido pela República do Chile, com a intensão solicitante de preservação e tombamento. $\mathrm{Na}$ ata contém a justificativa disposta como segue:

O Parque Nacional Rapa Nui contém evidências arqueológicas, que são constituídas principalmente pelos Moais (estátuas megalíticas/matéria vulcânica), que compõem as estruturas desde os templos cerimoniais, até vilas e casas, além de pinturas em paredes de gravuras rupestres. Isso se constitui em um património cultural único e notável (UNESCO, 1995a, p. 1, tradução nossa).

Conforme descrito no artigo primeiro da convenção da UNESCO de 1972, o sítio arqueológico de Rapa Nui, atendeu a mais de um critério, por eles estabelecidos e, assim, em dezembro de 1995, é anunciada a decisão do comitê, composto por 79

\footnotetext{
${ }^{2}$ Para efeito de uma análise sistêmica, menciona-se que todos os sítios arqueológicos aqui abordados atenderam aos requisitos do "artigo primeiro" da "Convenção Relativa à Proteção Mundial do Patrimônio Cultural e Natural" de 1972, celebrada em Paris, conforme segue:

Artigo 1: Para efeito da presente Convenção, os seguinte elementos devem ser considerados como 'patrimônio cultural':

- Monumentos: obras arquitetônicas, obras de escultura monumental e pintura, elementos ou estruturas de natureza arqueológica, inscrições, habitações em cavernas e combinações de registros em gravuras, que são de excepcional valor universal do ponto de vista da história, arte ou ciência;

- Conjuntos Arquitetônicos: agrupados ou separados, os edifícios que, em virtude de sua arquitetura, proporcionam integração na paisagem, ao ponto de serem indissociáveis, havendo homogeneidade de fato e, sem eles, há descaracterização do local, portanto, são de excepcional valor universal pelo ponto de vista da história, arte ou ciência;

- Lugares: obras humanas ou híbridas (de natureza humana e natural), compostas de sítios arqueológicos que são de excepcional valor universal, do ponto de vista histórico, estético, etnológico ou antropológico. (UNESCO, 1972, p. 2, tradução nossa).
} 
membros de 20 nacionalidades, dos quais os três com maior representatividade eram os alemães com $37 \%$, seguidos dos japoneses $11 \%$ e italianos $8 \%$, conforme segue abaixo:

\begin{abstract}
O Comité concluiu que o Parque Nacional Rapa Nui é um dos fenômenos culturais mais notáveis do mundo. Contém uma tradição artística e arquitetônica de grande capacidade inventiva desenvolvida por uma sociedade que era completamente isolada de referências culturais externas de qualquer tipo, por um período superior de um milênio. Os resquícios substanciais desta cultura que modelavam seus arredores naturais criaram uma paisagem cultural incomparável. Portanto, o Comitê decidiu incluir o Parque Nacional de Rapa Nui na Lista do Património Mundial com base em critérios. (UNESCO, 1995b, p. 49, tradução nossa).
\end{abstract}

Em 2013 houve uma retrospectiva das aprovações que, novamente, ratificaram o lugar como de excepcional valor universal, pois ainda se mantém preservado. Essa informação é relativamente importante, pois há lugares que, mesmo considerados como "Patrimônio da Humanidade", que vêm a ser degradados. Nota-se que a conscientização social onde este tipo de prática depredativa ocorre é dada em cidades que não dependem do turismo por visitações a patrimônios históricos, ficando como opcional, pois na maioria dos casos dependem, sobretudo, das belezas naturais e de razões econômicas.

O viajante britânico James Grant-Peterkin (2014) conta que, ao realizar sua primeira viagem à Ilha de Páscoa, ficou tão encantado com o que viu e resolveu tomá-la como objeto de estudo em sua dissertação de mestrado, apresentada a Universidade de Cambridge. Desde os anos 2000 desenvolveu sua própria agência de viagens e trabalha com o turismo no local e em 2009 foi nomeado cônsul britânico na Ilha (GRANTPETERKIN, 2014). James compartilha o conhecimento adquirido disponibilizando-o através de sua dissertação que se tornou livro, mas os meios de divulgação mais vistos são: o website da própria Ilha e seu blog particular (GRANT-PETERKIN, 2011). Nestas três fontes, ele sugere locais de visitação e compras, restaurantes, introduções à história e mapas do lugar.

No documentário feito pela emissora de televisão "BBC News" James declara: "este é um lugar muito difícil de deixar, uma vez que se esteve aqui por algum tempo [...], atualmente não tenho certeza se voltaria a viver no Reino Unido" (LONG, 2014, tradução nossa). O envolvimento do cônsul com o lugar tornou-se tão intenso, que durantes as duas primeiras semanas do mês de fevereiro, é ele quem estava apresentando o festival Tapati (GRANT-PETERKIN, 2014) A celebração única desta 
cultura envolve: músicas, danças e esportes tradicionais. Outro dado por ele realçado é de que o "festival sempre foi organizado pelos moradores e para os moradores, e não apenas com intuito de tornar-se um show comercial elaborado para turistas" (GRANTPETERKIN, 2011, tradução nossa). Sobre os visitantes, conclui que não são excludentes e, se por lá estiverem nesta época do ano, serão fortemente encorajados a participar e isso, certamente, será uma experiência memorável.

Para a visitante Ana Biselli (2013), sua atenção aparentemente recaiu sobre as grandes clareiras, pois comenta: "as florestas se foram, mas a cultura polinésia está mais viva do que nunca". Nota-se que este registro de Biselli vem de encontro ao pensamento sobre as questões de preservação e restauro, que asseguram a expectativa de se encontrar o original-intacto e, também, se concluem na associação de artes - arquitetura e festividade - vivas, permitindo mutabilidade. A luz desta consideração, a vitalidade expressa encontra-se nas relações sociais e no desenvolvimento antrópico cultural para domínio do ambiente. Por comparação as suas outras experiências a autora, associa sua recepção do aeroporto - pela a atuação dos nativos de Páscoa em brindar o turista com um colar de flores - ao Havaiano, dizendo: "por um momento me senti chegando novamente ao Havaî”. Enfatiza também, no aspecto icônico da paisagem, a grande quantidade de cavalos: “[...] estão ali, espalhados pela ilha, livres e soltos!”.

O viajante brasileiro Thiago Gambôa (2013), relata suas experiências e impressões, sobre partes do festival da seguinte forma:

\begin{abstract}
Um dos eventos mais aguardados é o Haka Pei, com as seguintes regras: o participante deve subir ao topo de um vulcão de mais de $300 \mathrm{~m}$ de altura e, trajando apenas uma tanga, descer sentado sobre dois troncos de bananeira amarrados um ao outro, formando uma espécie de trenó, chegando a velocidades próximas aos $80 \mathrm{~km} / \mathrm{h}$. [...]. Outra prova curiosa é o Tau'a, também no vulcão Rano Raraku. Essencialmente, é uma espécie de “triathlon”, mas ao invés de pedalar, os participantes atravessam a cratera do vulcão à remo em canoa, voltam a nado com uma prancha e correm em volta da mesma cratera com dois cachos de bananas sobre os ombros.
\end{abstract}

Para Gambôa (2013), as “principais atrações da Ilha de Páscoa são suas festas culturais, que promovem seus costumes ancestrais por meio de canções, danças típicas, vestimentas e outras tradições antigas”. Nota-se que as atrações mais enfatizadas deste autor, recaem prioritariamente sobre os esportes radicais. Diz-se isso porque em 
passagem posterior, o mesmo, apenas topicaliza as demais atrações do festival com comentários breves a respeito, conforme segue:

Takona: pintura corporal com elementos naturais; Vaka Tuai: recriar um barco tradicional polinésio e, em seguida, ir velejar no mar do Pacífico; Hoka Hako Opô: grupos musicais cantam alternadamente letras que não podem ser repetidas; Porã: Vestidos com trajes típicos, os concorrentes nadam com um flutuador de totora; Titinggi Mahauta: Trajes feitos com a planta Mahuate; Riu: em cantos rituais, as equipes contam as lendas e histórias de sua cultura. (GAMBÔA, 2013, p. 1).

De acordo com Claudia Martinelli (2013) sua estada na Ilha perpassa, a princípio, pelo mês agosto de 2012. Neste período ela constatou que eles já estavam se preparando para o festival Tapati, da seguinte forma: "costurando as fantasias das bailarinas e bailarinos, ensaiando coreografias, preparando obras de artesanato para participar de competições". Diferente do envolvimento que teve o cônsul James GrantPeterkin, Claudia faz planos de voltar, mas por hora solicita aos novos amigos, feitos por lá, que lhe enviem as notícias "dessa festa cheia do espírito dos ancestrais, ou seja, instinto puro, alegria, força, natureza e sensualidade”. E assim se fez, Claudia acompanhou, divulgou e publicou sobre o evento. Ao término de suas considerações, ela ainda evoca na imagem feminina, semelhança no estilo hulahula do Havaí nas dançarias, pela indumentária, se faz saber que entre as competidoras, quem apresentar melhor desempenho no visual e na dança, é eleita como "a rainha do festival".

As vivências apresentadas pelos quatro viajantes são indissociáveis do sítio arqueológico, o que confirma a hipótese de que o festival só exista por e com ele. Os comentários por eles impressos não confere exulto ao sítio, pois, no primeiro momento, quer se conhecer as esculturas totêmicas - os Moais, ícones do lugar -; posteriormente, a constância perceptiva destes monumentos espalhados por toda a Ilha, não se sobrepõe a interação social, que é dada de forma mais intensa, vivida e não contemplativa. Provavelmente, isto é o que justifica dos escassos a ausência de comentários registrados pelos viajantes sobre as estátuas e que lá estiveram durante a festividade (FIGURA 2). 
FIGURA 2 - MAPA E ILUSTRAÇÕES DAS ATIVIDADES DO FESTIVAL TAPATI, O GRANDE DESTAQUE É O HAKA PEI - UMA ESPÉCIE DE TRIATHLON QUE ENVOLVE: CANOAGEM, CORRIDA COM BANANA E DESLIZAR LADEIRA ABAIXO EM CIMA DE TRONCOS DE BANANA PELA DECLIVIDADE MAIS ÍNGREME DA ILHA; DURANTE A NOITE, FESTIVAIS E APRESENTAÇÕES DE DANÇA.

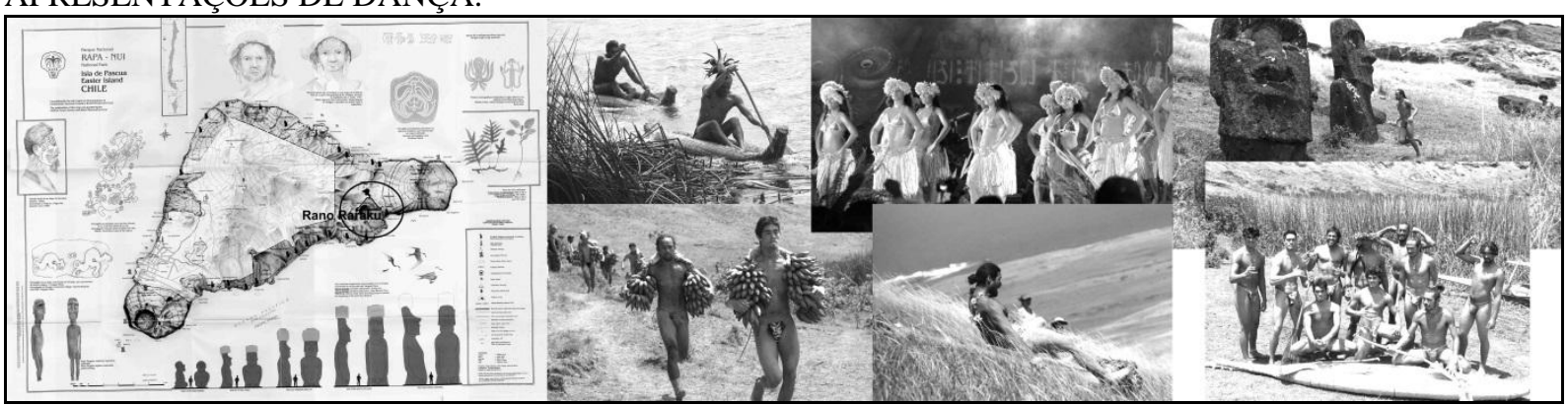

FONTE DO MAPA: UNESCO, 1984. FONTE DAS IMAGENS: GRANT-PETERKIN, 2014.

EDIÇÃO: O Próprio Autor.

\title{
3 CUSCO, PERU: O SÍTIO DE SACSAYHUAMÁN E O INTI RAYMI
}

Em 21 de junho de 1982, é protocolado à Assessoria de Avaliação da UNESCO, o pedido de listagem da Cidade de Cusco como Patrimônio da Humanidade, feito pela República do Peru (UNESCO, 1983).

\begin{abstract}
Cusco é hoje um amálgama surpreendente entre a Capital do Imperador Inca e a cidade colonial espanhola. A princípio ela preserva vestígios impressionantes, especialmente em seu planejamento: paredes de granito meticulosamente cortadas, ruas retilíneas se formam dentro dos muros, as ruínas do Templo do Sol e o Jardim Dourado, que uma vez fora coberto com esculturas de metais preciosos, mas saqueada pelos soldados espanhóis, enviando-as para enriquecer os cofres de Charles V. Da cidade colonial, resta apenas casas bem conservadas em suas fachadas e pútridas internamente, os palácios e as maravilhosas igrejas barrocas atingiram uma fusão improvável, entre a tradição inca com a do colonizador espanhol. (UNESCO, 1983, p. 2, tradução nossa).
\end{abstract}

A inscrição de Cusco na lista dos patrimônios mundiais foi baseada nos critérios da Convenção da UNESCO de 1972, cumprindo, assim, seus requisitos do artigo primeiro. Desde 1983 o Comitê aprovou a solicitação e o enquadrou em sua listagem, além disso, recomendou, que, para reforçar o valor cultural e natural desta propriedade, o sítio deveria estender as fronteiras de preservação além da cidade de Cusco, margeando pelo Rio Urubamba, e das fortalezas de Pisac e Ollantaytambo, que compõem o Vale Sagrado. 
Inúmeras foram as reuniões e conferências desde então, mas em 2015 o relatório da UNESCO adverte alguns fatores que estavam impactando negativamente na área e afetavam a propriedade, identificada como um "bem comum", conforme abaixo. Portanto, é do interesse de todas as nações zelarem pela preservação, entre os itens exigidos, nesta pesquisa, é relativamente importante destacar:

\footnotetext{
- A falta de estudos de impacto relacionados com a capacidade de carga da Cidadela.

- Atrasos na implantação de medidas de planejamento e controle do acesso urbano para Machu Picchu, pois o principal ponto de entrada é a cidade de Cusco, os impactos são tamanhos que são perceptíveis e podem ser mensurados pelo campo visual nas propriedades.

. Não há qualquer avaliação de opções de transporte, relacionadas com estudos geológicos, ou o impacto gerado pelo tráfego de ônibus que incide no aumento do risco de deslizamentos de terra. (UNESCO, 2015, p.1, tradução nossa).
}

Entre os demais tópicos citados na ata, influem diretamente na cidadela de Machu Picchu, não se referindo à Cusco e extensão. Isso se faz importante saber, porque o festival Inti Raymi não tem qualquer vinculação com o sítio arquitetônico e arqueológico de Machu Picchu.

A expressão máxima da Cultura Quéchua tem como rito cerimonial a grande festa Inti Raymi, que é oferecido ao Deus Sol, o deus do Imperador Inca (EMUFEC, 2013). Em visita do autor ao país, se fez interessante saber algumas particularidades sobre estas nomenclaturas, que até então são pouco exemplificadas, começando pelo termo amplamente difuso: "Cultura Inca", o correto é "Cultura Quéchua”, faz-se saber que Inca é o título do regente, da mesma forma que o Faraó para os egípcios. O idioma utilizado por esta antiga civilização é o "quíchua", a tradução apresentada do título da festividade é: Inti correspondente a sol e Raymi a festa.

Sem se atentar as questões passadistas, narradas pelo cronista Garcilaso de la Veja, sobre o último ritual celebrado em 1535, quando então foi proibido pela igreja católica por ser uma festa pagã e após 409 anos mantidos no esquecimento, a encenação foi remontada, pelo pesquisador Faustino Espinoza Navarro (EMUFEC, 2013). O evento foi reconstituído em três partes - Templo del Sol: Qoricancha, posteriormente Plaza de Armas, encerrando-se na Fortaleza de Sacsayhuamán - e articula uma lógica espacial própria entre os lugares. As pessoas que participam da encenação utilizam-se de fantasias de pouca roupagem, mesmo diante da baixa temperatura, tal esforço se 
justifica para manter a tradição viva, para si mesmos e para os espectadores. As duas primeiras partes da encenação são gratuitas e abertas ao público de modo geral; a última, e a mais emblemática, é privada e pouco acessível aos residentes devido aos altos custos. Por se tratar do maior evento do país, a população que não pode pagar para ficar nas arquibancadas, comumente, ocupada por turistas e pessoas de maior poder aquisitivo, se acomodam no alto dos relevos e, até mesmo, em cima das árvores para prestigiar, lá de longe, o espetáculo de sua própria cultura ${ }^{3}$.

À luz de tais distinções analíticas, o festival começa às oito horas da manhã, na praça do templo de Qoricancha (EMUFEC, 2015). De acordo com a Empresa Municipal de Festejos del Cusco - EMUFEC (2013, p. 1), "lá é a construção mais importante da cultura daquele povo, centro de toda civilização, pois representava a distribuição geográfica e administrativa do império". Tendo o templo como eixo central, são traçadas duas linhas diagonais cruzadas, um verdadeiro " $\mathrm{x}$ ", que divide o império em quatro cantos, representando os pontos cardeais. Na semana que precede o evento, no lado externo do templo, é colocado um disco dourado que simboliza o astro deus. Dali, a cena que se desenvolve todos os anos no dia 24 de junho, é ritmada por sons de flautas, batuques e outros instrumentos, aparece o Regente, o Sumo-sacerdote, os guardas que se distinguem pela indumentária, acompanhados por homens e mulheres, aparentemente comuns, que desempenham funções diversas. A cerimônia vai se avolumando, recebendo gradativamente diversos atores e atrizes, que vão chegando e representando as tribos dos quatro cantos, pertencentes ao antigo império, que se diferenciam pela coloração da roupa. Tudo isso evoca no imaginário passado, os tempos de percursos que estes povos andinos custavam a fazer e a importância desta confraternização, não apenas do ponto de vista político-religioso, mas também social.

O segundo ato da celebração acontece na Plaza de Armas. As ruas são tomadas em polvorosas. Neste ponto confluem atores e espectadores, onde o último a chegar à cerimônia é o Inca. Mas isso poucos percebem, pois a articulação estabelecida entre o conjunto arquitetônico e o público, acaba por dispersar a atenção devido ao uso dos estabelecimentos ao redor. Em sua visita, Arnóbio Neto (2014) faz uma colocação de algo que ocorreu com sua família, a mesma é replicante aos visitantes que "saíram

\footnotetext{
${ }^{3}$ N. A.
} 
entrando em tudo quanto é loja da Plaza de Armas ${ }^{4}$. E são muitas”. Este é considerado o ponto mais fraco do ritual e, também, o mais rápido. Logo, os viajantes acabam por não compreendê-lo e o percurso segue para seu terceiro ato - o sacrifício da alpaca descrito abaixo.

A fortaleza de Sacsayhuamán é um importante registro arquitetônico desta cultura, pois, assim como em outros templos, era constituído de grandes rochas recortadas, que eram cuidadosamente encaixadas e empilhadas, sem o uso de argamassa (EMUFEC, 2013). A parte mais importante do ritual tem seu desfecho, o público, principalmente estrangeiro, contempla a cerimônia das arquibancadas e, novamente, tem-se a chegada das tribos, com seus ritos e suas danças, que precedem a chegada do Inca e o Sumo-sacerdote ${ }^{5}$. O auge da cerimônia acontece quando trazem ao palco, um filhote de alpaca, que era sacrificado ali mesmo, no altar, extraindo do peito seu coração e vísceras, além de serem apresentados para todo o público (EMUFEC, 2013). Para eles, o significado disso era revelar presságios sobre o clima e a colheita, se a faca não atingisse os órgãos do animal no abate, era bom sinal, caso contrário, passariam por tempos difíceis (EMUFEC, 2013).

O vivido que aqui se apresenta é dado de forma intensa, evocando na revitalização do ritual as memórias de outros tempos. Para o viajante Felipe Floresti (2012, p. 1) "uma viagem pelos territórios andinos reserva muito mais ao viajante do que simplesmente belezas naturais e valores arqueológicos". Leva o espectador a sensação de ser integrante do rito, como as pessoas comuns de tempos passados provavelmente se sentiam ${ }^{6}$. As vivências coletadas pouco divergem ou se sobrepõem, pois a maioria narra e descreve as três etapas que assistiram (FIGURA 3). Assim, os sítios arqueológicos adquirem fundamental importância para assimilar e reconstituir as cenas das confraternizações, mesmo que de forma imaginária e ficcional, de um determinado período.

\footnotetext{
${ }^{4}$ N. A.

${ }^{5}$ N. A.

${ }^{6}$ N. A.
} 
FIGURA 3 - MAPA DE CUSCO E O FESTIVAL INTI RAYMI: TEMPLO DE QORICANCHA (A ESQUERDA); PLAZA DE ARMAS EM CUSCO (A DIREITA) E FORTALEZA DE SACSAYHUAMÁN (NA PARTE INFERIOR).

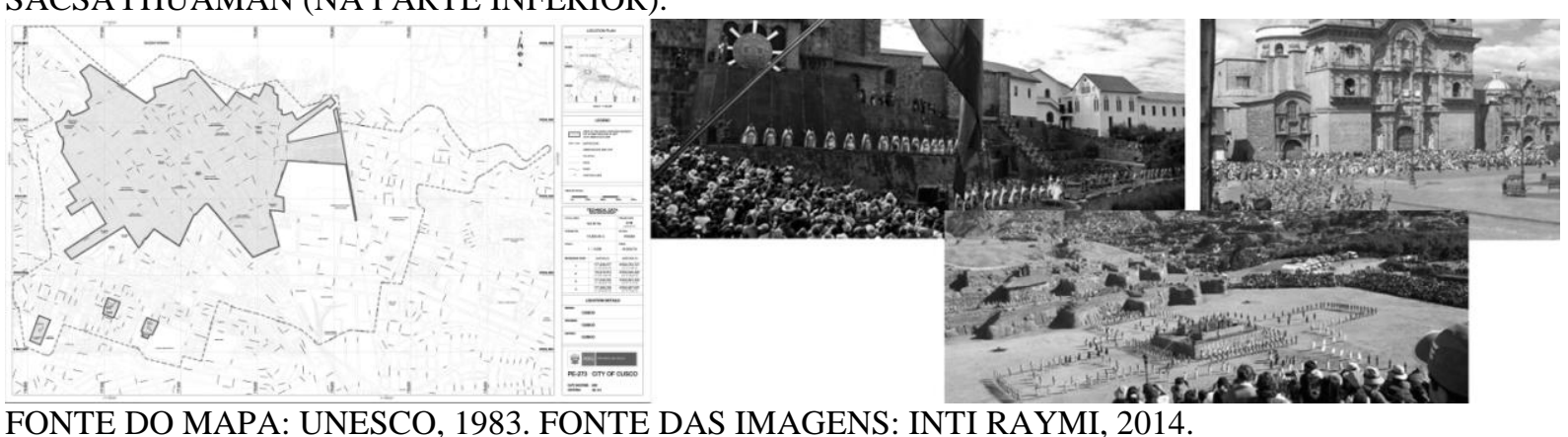

\section{PALENQUe, MÉXico: A tUMba de PAKal E O Ritual EM HOMENAGEM AOS MORTOS}

Em 1987 a Assessoria de Avaliação da UNESCO aprovou o pedido do México da listagem do sítio arqueológico de Palenque, reconhecendo-o como Patrimônio da Humanidade (UNESCO, 1987). Localizado no âmago de uma floresta tropical, as ruínas constituem-se de uma área de aproximadamente oito quilômetros quadrados e atendem aos seguintes critérios:

\footnotetext{
- Palenque é um incomparável legado pertencente à arte dos Maias. As estruturas são caracterizadas por sutileza e leveza, apresentam um novo modelo construtivo com relação às espessuras das paredes e um sistema de drenagem que foram desenvolvidos em nível onde eram cultivados os jardins, além de amplos espaços interiores com múltiplas aberturas, por si, dão a arquitetura um ar de elegância combinado aos glifos, ornamentos decorativos esculpidos nas paredes, de um tipo, até então, nunca visto.

. A influência exercida por Palenque compreende muito além das bacias de Usumacinta, ao oriente estendendo-se até Comalcalco, a antiga fronteira ocidental do império Maia.

. Palenque comporta em si, o único testemunho mitológico e ritualístico dos Maias, notável pela inacreditável quantidade de esculturas nas paredes dos palácios e dos templos.

. O conjunto das edificações cerimonialíssimas de Palenque são excelentes exemplos dos santuários do período clássico Maia, inclusive, anterior ao conjunto de Tikal maior monumento construído cem anos depois (UNESCO, 1987, p. 1, tradução nossa).
}

Em novembro de 2008, na cidade de Istambul, a UNESCO iniciou a listagem dos patrimônios culturais intangíveis, ou imateriais e, diferente dos outros dois festivais desta abordagem, este se distingue por fazer parte desta lista em transcender a escala 
local, atingindo a mundial (UNESCO, 2008). Entre as indagações feitas no início deste artigo, este evento foi adaptado a inúmeras culturas, sobretudo a norte-americana, pois, dentro do período de sua realização dá-se o helloween; celebrado em 31 de outubro, e a ambiência de morbidez estende-se até o dia 2 de novembro, dia de finados, conforme estipulado pela igreja católica respectivamente início e fim da celebração original (ESTRADA, 2014). Outro fator de diferenciação do evento está relacionado aos impactos econômicos, que, neste caso, não exercem representatividade, portanto é prioritariamente a celebração de uma tradição popular local e cultural entre os próprios residentes. Faz-se saber que em 2003 o festival, no México já era proclamado como patrimônio da humanidade, por parte da população, mas não era oficialmente reconhecido em registro, devido à ausência de critérios, ainda não estabelecidos pelos órgãos competentes (UNESCO, 2008).

Cinco anos mais tarde, a descrição apresentada pelo governo à entidade sobre o festival é a seguinte:

\begin{abstract}
No dia dos mortos se comemora o retorno das almas para o mundo dos vivos, das almas de parentes e entes queridos já falecidos. As festividades ocorrem todos os anos no período compreendido entre o final do mês de outubro e início de novembro. Este período coincide também, com o término do ciclo anual de cultivo do milho, alimento predominante na cultura do país [...] As famílias acreditam facilitar o retorno das almas para a Terra e ao longo do trajeto que conduz do cemitério para suas casas, colocando pétalas de flores, velas e oferendas que, normalmente, são os pratos favoritos do(s) falecido(s) os quais são colocados em torno do santuário da casa e do respectivo túmulo, acompanhado de artesanatos típicos. Todo este capricho é merecedor de grande cuidado, pois, acredita-se que os mortos são capazes de trazer prosperidade ou o infortúnio sobre suas famílias, dependendo do quão satisfatório for, para as almas, a execução do ritual [...] Este encontro, entre vivos e mortos, tem como intuito honrar e consolidar a posição social deixada pelo indivíduo para a família, perante toda a sociedade, contribuindo assim, para reforçar sua posição social e política na comunidade indígena do México. [...] A fusão deste rito religioso indígena pré-colombianos, incorporados pelas festas católicas, reúne o melhor deste campo cultural, marcado por sistemas de crenças que não deixaram se sobrepor pelas visões trazidas dos europeus no século XVI (UNESCO, 2008, p. 1, tradução nossa).
\end{abstract}

De acordo com a entrevista feita por Luís Estrada (2014, p. 1) ao arqueólogo Alfonso Morales, o mesmo considera que:

[...] o dia dos mortos foi adotado entre os Maias para evitar confrontos e continuar a exercer seus ritos frente à influência da igreja católica na colônia, no entanto, os Maias nunca tiveram uma data exata para isso, era o término da colheita que determinava o período da comemoração. 
Outro dado, por Estrada (2014, p. 1) realçado, refere-se a Tumba de Pakal no Templo de Palenque, onde as inscrições contidas nas paredes do Templo representam a mais precisa das informações dos rituais funerários que esta civilização costumava praticar e destacam: “O templo das inscrições, é o maior monumento funerário Latinoamericano, a pirâmide dedicada ao governante, foi desenhada pelo próprio Pakal para ser seu lugar de descanso". Os glifos encontrados no interior da tumba, são verdadeiras metáforas que, provavelmente, remetem a herança da vida terrena deixada pela governante, o que mais se destaca esta na forma de uma serpente e um broto de milho, o qual se acredita representar seu filho (ESTRADA, 2014).

Um documentário feito pela rede Discovery-Channel indica uma hipótese sobre o enfraquecimento da civilização maia, que se deu pelo excesso de sacrifícios e, consequentemente, pela contaminação das águas. Diferente do que acontece desde a fusão dos ritos religiosos, incorporados no catolicismo, antigamente o ritual demorava cerca de um mês e as pessoas mutilavam seus corpos, com a perda de muito sangue, entravam em transe, desta forma acreditavam que era possível comunicar-se com os mortos e muitos morriam neste percurso (DISCOVERY, 2012).

Destacam-se, também, outras três curiosidades sobre o evento: a primeira, refere-se à modernização dos costumes que substituiu as oferendas de sangue pelos doces açucarados pintados de vermelho, esta ideia veio dos colonizadores em dizer que os mortos agradavam-se igualmente destes; o outro, é de que a cor da morte, no México pré-hispânico, era amarela, a mesma de uma flor típica do país, denominada cempasúchil; e, por fim, de que as festividades eram presididas pela deusa da morte Mictecacihuatl, atualmente conhecida como "La Catrina” (DISCOVERY, 2012).

De acordo com as impressões do viajante André Romera (2013), o passeio por ele feito se deu em um balão onde descreve: "é muito legal ver as pirâmides lá de cima, [...] de todas que eu já visitei foi uma das melhores. Quando o balão aterrissa, te levam de volta para a base, e de lá, te levam para as ruínas. Subir na gigantesca pirâmide é algo que você tem que fazer". Externo aos sítios arqueológicos, André ainda destaca que se sentiu seguro nas ruas dos bairros devido a quantidade de policiais, mas que a criminalidade era alta.

O vivido que aqui se apresenta é dado especialmente nos trajetos, pois envolve o caminho dos cemitérios até as residências. Neste caso, os templos e os sítios 
arqueológicos pouco interferem no festival, pois este ocorre especialmente nas ruas das cidades, que são apropriadas pelas pessoas comuns, todos são convidados a participar e se caracterizarem de caveira, símbolos do último estágio da "evolução" humana (UNESCO, 2008). A relação que se estabelece entre a cultura material, o sítio arqueológico (FIGURA 4) é de que, a partir dele, foram restaurados os registros que confirmam o ritual, a cultura imaterial (UNESCO, 1987).

FIGURA 4 - MAPA DO SÍTIO ARQUEOÓGICO DE PALENQUE; AO LADO, CELEBRAÇÃO DA FESTA DOS MORTOS NO CEMITÉRIO DE PALENQUE; NA PARTE SUPERIOR A DIREITA, TEMPLOS DE PALENQUE; ABAIXO NA EXTREMA DIREITA, O TEMPLO DAS INSCRIÇÕES, EM FORMATO DE PIRÂMIDE.

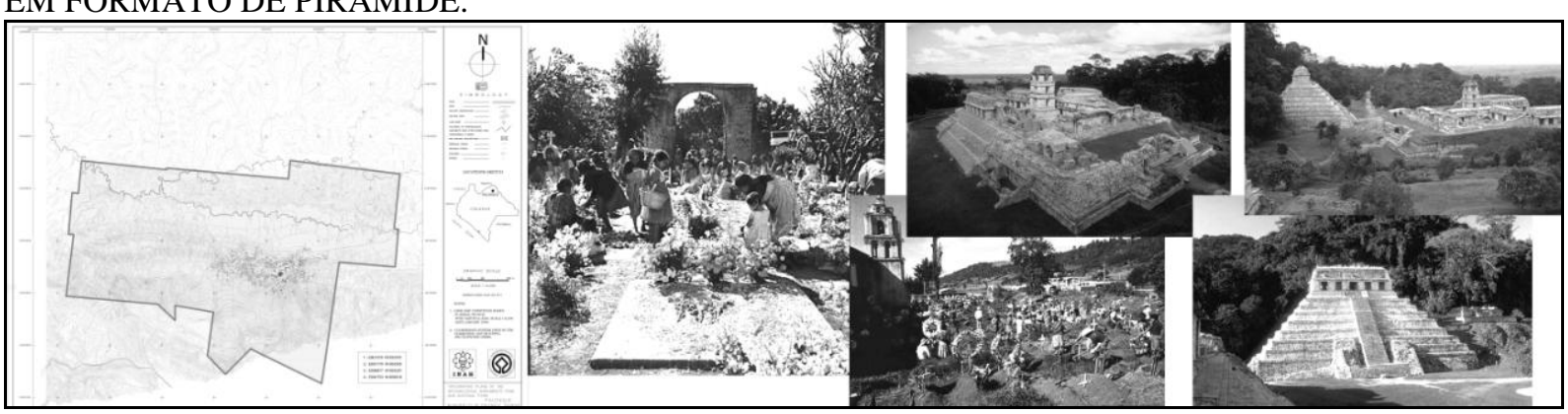

FONTE DO MAPA E IMAGENS: UNESCO, 1987.

FOTÓGRAFO: Martin Gray.

EDIÇÃO: O Autor.

\section{CONSIDERAÇÕES FINAIS}

Em uma busca quase etnográfica, foram recolhidos através do discurso - das impressões dos viajantes - e da iconografia, todos os possíveis elementos da paisagem e dos festivais em seus traços mais restritos, os quais sensibilizam a atenção investigativa às circunstâncias fugazes da modelagem do espaço vivido para os eventos.

Desse ponto de vista, a orientação teórico-metodológica favoreceu a apreensão das vicissitudes históricas, sociais e culturais, das civilizações passadas que perduram até o tempo presente, ao promover o encontro entre o material e o imaterial. Ambos convergiram em uma mesma busca: aproximar-se da vida que se fez, e ainda se faz, corporalmente no e pelo espaço. Assim, revelaram-se e transformaram-se em virtudes os usos, sejam estes dos costumes e tradições passadas quanto dos sítios arqueológicos, para além das evidentes qualidades formais da visitação cotidiana. 
Neste artigo, a interligação biunívoca entre as datas comemorativas e os sítios arqueológicos foram apresentados de forma mais intensa, sobretudo nos "eventos de turismo", que consagram a região pelo grande fluxo de turistas. E eis que emergem os resultados obtidos após a elaboração desse artigo, pois, tais elementos festivos só existem pela existência dos sítios arqueológicos ao compreender seu significado original às civilizações dos tempos passados. Assim, as práticas de preservação e restauração - sejam estes do material (os sítios) e imaterial (os eventos) -, que se renovam a cada ano, na plenitude de seu vigor pela data estabelecida, e adquirem sentido real na transmissão destes à sociedade, que visa recolocar seus bens patrimoniais no jogo do tempo presente; especialmente pela prática turística, que visa, também, rentabilidade e a manutenção destes bens.

Por tudo isso, nessa perspectiva, ao relativizar as vivências: das celebrações no local originalmente proposto para tal feito, se abrem a produção histórica contemporânea social e cultural do lugar, da qual faz sentido para a população dessa época. Convidativo a nacionais e estrangeiros a oportunidade desse convívio tão honroso imerso nas festividades, onde preservar parece ser uma ação interventiva de um processo de ressignificação e, daí uma recriação, que se faz sobre a quintessência de elementos que conseguiram sobreviver ao tempo.

\section{REFERÊNCIAS}

BISELli, A. Os 1.000 dias de Ana Biselli. 1.000 dias por toda a América. 10 Out. 2013. Disponível em: <http://www.1000dias.com/ana/rapa-nui/>. Acesso em: 09/10/2015.

CARSALADE, F. L. A preservação do patrimônio como construção cultural. Arquitextos, São Paulo. ano 12, n.139.03, de Vitruvius, dez. 2011. Disponível em: <http://www.vitruvius.com.br/revistas/read/arquitextos/12.139/4166>. Acesso em: 22/12/2014.

DISCOVERY. Civilizações Perdidas - Maia: Sangue de Reis, Duração: 46:45. Direção: Produzido e Escrito por: Jason Williams. 2012.

EMUFEC. Empresa Municipal de Festejos del Cusco. Inti Raymi "1 CD-ROM." Diretor Geral Inti Raymi 2013: NINA, Lino Sánchez, 24 Jun. 2013.

Inti Raymi 2015: Escenarios. Fiestas del Cusco. 2015. Disponível em: <http://www.emufec.gob.pe/es/>. Acesso em: 10/10/2015. 
ESTRADA, L. A. Revista Quo: EI Día de Muertos entre los mayas. La muerte para esta cultura representa 'un viaje a otro mundo'. 31 Out. 2014. Disponível em: <http://quo.mx/noticias/2014/10/31/el-dia-de-muertos-entre-los-mayas>. Acesso em: 09/10/2015.

FLORESTI, F. Maior festa da cultura inca, Inti Raymi acontece em Cusco; conheça a cultura dos povos andinos. UOL viagem. 19 Jun. 2012. Disponível em: $<$ http://viagem.uol.com.br/noticias/2012/06/19/maior-festa-da-cultura-inca-inti-raymiacontece-em-cusco-conheca-a-cultura-dos-povos-andinos.htm>. Acesso em: $10 / 10 / 2015$.

GAMBÔA, T. Fevereiro: Tapati Festival na Ilha de Páscoa. Via Br Blog. 07 Fev. 2013. Disponível em: <http://www.viabrblog.com.br/todos-os-posts/o-mundo-na-hora-certafevereiro-tapati-festival-na-ilha-de-pascoa/>. Acesso em: 08/10/2015.

GRANT-PETERKIN, J. Companion To Easter Island. South Pacific Blog. 20 Fev. 2011. Disponível em: <http://blog.southpacific.org/companion-to-easter-island>. Acesso em: 08/10/2015.

Tapati Festival. Easter Island Spirit. 2014. Disponível em: <http://www.easterislandspirit.com/tapati-festival.html>. Acesso em: 09/10/2015.

INTI RAYMI. In: Agencia Operadora de Viajes en Perú y Latinoamerica. Base de dados das imagens: Qoricancha; Plaza de armas Cusco; Fortaleza de Sacsayhuamán. 2014. Disponível em: <http://www.intiraymi.org/>. Acesso em: 10/10/2015.

LEFEBVRE, H. Critique de la vie quotidienne (vol. 1: Introduction). Paris: L'Arche Éditeur, 1974 [ed.1958].

LONG, G. BBC News, Hanga Roa, Easter Island. Easter Island's lone honorary consul. 16 de Mai de 2014. Disponível em: <http://www.bbc.com/news/world-latinamerica-27389860>. Acesso em 08/10/2015.

MARTINELli, C. Tapati - Rapa Nui - Festival Ilha de Páscoa. Vai na minha, relatos de viagem: o que deu certo e o que deu errado! Sugestões para uma viagem inesquecível. 22 Jan. 2013. Disponível em:

<http://www.vainaminha.com/2013/01/tapati-rapa-nui-festival-iha-de-pascoa.html>. Acesso em: 09/10/2015.

NETO, A. Planejamento, roteiros, dicas, relatos e experiências de viagem. Meus Planos de Viagem. 27 de Dez de 2014. Disponível em: $<$ https://meusplanosdeviagem.wordpress.com/>. Acesso em: 10/10/2015.

ROMERA, A. Roteiro Cidade do México, Palenque, Yucatán e Caribe. 24 Mar. 2013. Disponível em: <http://www.mochileiros.com/roteiro-cidade-do-mexicopalenque-yucatan-e-caribe-jan-2013-t75461.html>. Acesso em: 12/10/2015. 
SANTOS, M. A Natureza do Espaço: Técnica e Tempo, Razão e Emoção. São Paulo: Edusp, 1996 [4. ed. 2012].

SARLO, B. A Cidade Vista: mercadorias e cultura urbana [trad. Mônica Stahel]. São Paulo: WMF Martins Fontes (coleção cidades), 2014 [orig. 2009].

UNESCO. United Nations Educational Scientific and Cultural Organization. "City of Cuzco: Documents - Advisory Body Evaluation." World Heritage Convention. 1983. Disponível em: <http://whc.unesco.org/archive/advisory_body_evaluation/273.pdf>. Acesso em: 09/10/2015.

Convention Concerning the Protection of the World Cultural and Natural Heritage. Adopted by the General Conference at its seventeenth session Paris. 16 Nov. 1972. Disponível em: 〈http://whc.unesco.org/archive/convention-en.pdf〉. Acesso em: 04/10/2015.

Convention Concerning the Protection of the World Cultural and Natural Heritage. Nineteenth Session Berlin, Germany. Dez. 1995a. Disponível em: <http://whc.unesco.org/archive/1995/whc-95-conf203-16e.pdf>. Acesso em: 04/10/2015.

Factors affecting the property in 2015. World Heritage Convention. 2015. Disponível em: <http://whc.unesco.org/en/soc/3257>. Acesso em: 09/10/2015.

Indigenous festivity dedicated to the dead. Intangible Cultural Heritage. Third Session of the Intergovernmental Committee (3.COM) - Istanbul, 4 to 8 Nov 2008. Disponível em: <http://www.unesco.org/culture/ich/RL/00054>. Acesso em: 09/10/2015.

. Pre-Hispanic City and National Park of Palenque. Description Documents: Advisory Body Evaluation. 1987. Disponível em: <http://whc.unesco.org/en/list/411/documents/>. Acesso em: 10/10/2015.

World Heritage Convention. Rapa Nui National Park. Advisory Body Evaluation de 13 Jun. 1995b. Disponível em: <http://whc.unesco.org/archive/advisory_body_evaluation/715.pdf >. Acesso em: 04/10/2015.

Map Rapa Nui National Park. Inscribed property. 1984. Disponível em: <http://whc.unesco.org/en/list/715/multiple=1\&unique_number=846>. Acesso em: 04/10/2015.

Recebido em: 17-06-2016.

Aprovado em: 17-07-2016. 